\title{
GAMBARAN OHI-S DAN PERILAKU MENYIKAT GIGIPADA SISWA KELAS VI SDN 5 PEKUTATAN KECAMATANPEKUTATAN KABUPATEN JEMBRANA TAHUN 2016
}

\author{
Ni Putu Vinarini Puspita, ${ }^{1}$ S. Ni Made Sirat ${ }^{2}$ \\ ${ }^{1,2}$ Jurusan Kesehatan Gigi Poltekkes Denpasar \\ made_sirat@yahoo.com
}

\begin{abstract}
Improve oral health is one of the efforts made in the maintenance of dental health from an early age. The level of oral hygiene can be measured by an index that is Oral Hygiene Index Simplified (OHI-S). The most easy way to maintain hygiene and oral health by tooth brushing. Tooth brushing behavior is good and right that is done persevering,conscientious, and regular. This study aims to determine theDescription of OHI-S and Tooth Brushing Behavior in Grade VI SDN 5 Pekutatan Sub District Pekutatan at Regency Jembrana Year 2016. This research use study descriptive and this study use the total population of 34 students of SDN 5 Pekutatan Year 2016. The results of this research indicate that student's OHI-S with good criteria as many as five students (14.7\%), the medium criteria as many as 26 students (76.5\%), and bad criteria as many as three students (8.8\%). whereas in tooth brushing behavior totaling 34 students included in the criteria necessary guidance.OHI-S at grade sixth students who have the most OHI-S criteria with the criteria medium, whereas most brushing behavior criteria skills need brushing guidance.Grade VI students to pay more attention toothbrushing behavior is good and right.
\end{abstract}

Keywords: OHI-S, Tooth brushing behavior

Abstrak. Meningkatkan kesehatan gigi dan mulut merupakan salah satu upaya yang dilakukan dalam pemeliharaan kesehatan gigi dan mulut sejak usia dini. Tingkat kebersihan gigi dan mulut dapat diukur dengan suatu index yaitu Oral Hygiene Index Simplified (OHI-S). Cara yang paling mudah dilakukan untuk menjaga kebersihan serta kesehatan gigi dan mulut dengan menggosok gigi. Perilaku menyikat gigi yang baik dan benar yaitu dilakukan secara tekun, teliti, dan teratur. Penelitian ini bertujuan untuk mengetahui gambaran OHI-S dan Perilaku Menyikat Gigi pada Siswa Kelas VI Di SDN 5 Pekutatan Kecamatan Pekutatan Kabupaten Jembrana Tahun 2016. Penelitian ini merupakan penelitian deskriptif dengan total populasi sebanyak 34 siswa di SDN 5 Pekutatan Tahun 2016. Hasil penelitian menunjukkan $O H I-S$ dengan kriteria baik sebanyak lima orang $(14,7 \%)$, kriteria sedang 26 orang $(76,5 \%)$, dan kriteria buruk tiga orang $(8,8 \%)$, sedangkan perilaku menyikat gigi siswa termasuk dalam kriteria perlu bimbingan. Siswa kelas VI memiliki kriteria $O H I-S$ terbanyak dengan kriteria sedang, sedangkan perilaku menyikat gigi terbanyak dengan kriteria keterampilan menyikat gigi perlu bimbingan. Disarankan agar siswa kelas VI lebih memperhatikan perilaku menyikat gigi dengan baik dan benar.

Kata Kunci: $O H I-S$, Perilaku Menyikat Gigi 
Pendahuluan

Kesehatan mulut merupakan bagian fundamental kesehatan umum dan kesejahteraan hidup. Kesehatan gigi atau sekarang sering disebut sebagai kesehatan mulut adalah kesejahteraan rongga mulut, termasuk gigi geligi dan struktur serta jaringan-jaringan pendukungnya bebas dari penyakit dan rasa sakit, serta mulut berfungsi secara optimal. $^{1}$

Riset Kesehatan Dasar 2013 menyatakan bahwa sebesar 24,0\% penduduk Provinsi Bali mempunyai masalah dengan kesehatan gigi dan mulut, sedangkan penduduk bermasalah dengan gigi dan mulut yang mendapatkan perawatan atau pengobatan dari tenaga medis sebanyak 38,8\% serta gigi yang sudah ditambal sebanyak 9,31\%. Penduduk Kabupaten Jembrana, yang mengalami masalah kesehatan gigi dan mulut adalah sebanyak $28,8 \%$ dan penduduk yang sudah mendapatkan perawatan atau pengobatan sebanyak $35,8 \%$ serta $10,31 \%$ gigi karies yang sudah ditambal dan $91,8 \%$ penduduk di Provinsi Bali yang berumur sepuluh tahun ke atas menyikat gigi setiap hari, namun hanya $4,1 \%$ yang berperilaku benar dalam menyikat gigi (menyikat gigi sesudah makan pagi dan malam sebelum tidur). Sedangkan presentase penduduk di Kabupaten Jembrana yang menyikat gigi setiap hari $92,7 \%$ dan yang berperilaku benar dalam menyikat gigi sebanyak $1,5 \%{ }^{2}$

Hasil penelitian, ${ }^{3}$ pada siswa kelas V SD Pelayanan Asuhan Jurusan Keperawatan Gigi Poltekkes Kemenkes Denpasar menunjukkan bahwa presentase $O H I-S$ dengan kriteria baik sebanyak 32 orang $(49,23 \%)$, sedangkan kriteria sedang sebanyak 29 orang (44,62\%), dan kriteria buruk sebanyak empat orang (6,15\%). Rata-rata kebersihan gigi dan mulut siswa kelas $\mathrm{V}$ SD Pelayanan Asuhan Jurusan Keperawatan Gigi Poltekkes Kemenkes Denpasar adalah 1,6 dengan kriteria sedang. Hasil penelitian tentang perilaku menyikat gigi diperoleh presentase siswa yang berperilaku menyikat gigi benar sebanyak 58,46\% dan berperilaku menyikat gigi salah sebanyak 41,53\%.

Kebersihan gigi dan mulut adalah suatu keadaan yang menunjukkan bahwa di dalam mulut seseorang bebas dari 
kotoran seperti debris, plak, dan kalkulus. Meningkatkan kesehatan gigi dan mulut merupakan salah satu upaya yang dilakukan dalam pemeliharaan kesehatan gigi dan mulut sejak usia dini. Tingkat kebersihan gigi dan mulut dapat diukur dengan suatu index yaitu Oral Hygiene Index Simplified (OHI-S).

Cara yang paling mudah dilakukan untuk menjaga kebersihan serta kesehatan gigi dan mulut dengan menggosok gigi. Perilaku menyikat gigi yang baik dan benar yaitu dilakukan secara tekun, teliti, dan teratur. Menyikat gigi adalah rutinitas yang penting dalam menjaga dan memelihara kesehatan gigi dari bakteri dan sisa makanan yang melekat dengan menggunakan sikat gigi. Menyikat gigi merupakan suatu upaya yang dilakukan untuk menjaga agar gigi tetap dalam keadaan yang bersih dan sehat

Anak usia 12 tahun penting sekali, oleh karena itu usia 12 tahun digunakan sebagai usia yang tepat untuk memantau kesehatan gigi dan mulut, karena anak umur 12 tahun pada umumnya akan meninggalkan sekolah dasar, sehingga merupakan usia yang mudah dijangkau oleh karena itu usia 12 tahun digunakan sebagai usia untuk memantau karies gigi secara global (global caries monitoring age) untuk dibandingkan secara Internasional. ${ }^{4}$

Tujuan dari penelitian adalah untuk mengetahui gambaran $O H I-S$ dan perilaku menyikat gigi pada siswa kelas VI di SDNo. 5 Pekutatan tahun 2016. Penelitian ini merupakan penelitian deskriptif dengan desain survey. Penelitian dilaksanakan pada seluruh siswa kelas VI SD No.5 Pekutatan Kecamatan Pekutatan, Kabupaten Jembrana yang berjumlah 34 orang.

\section{Hasil Penelitian}

Sekolah Dasar Nomor 5 Pekutatan Kecamatan Pekutatan, Kabupaten Jembrana, terletak di Jalan Denpasar Gilimanuk, Desa Pekutatan, Kecamatan Pekutatan. Tenaga pengajar yang ada di sekolah ini sebanyak delapan orang, satu orang kepala sekolah, enam orang guru dan satu orang staf Tata Usaha.

\section{Karakteristik subyek penelitian}

Siswa kelas VI SD No. 5 Pekutatan, Kecamatan Pekutatan, 
Kabupaten Jembrana Tahun 2016 Pekutatan Tahun 2016 didapatkan hasil berjumlah 34 orang, 18 laki-laki dan 16 sebagai berikut : perempuan. Hasil penelitian di SD No. 5

a. Persentase responden dengan kriteria $O H I-S$ baik, sedang, dan buruk

Tabel 1

Persentase OHI-S Siswa Kelas VI SDN 5 Pekutatan Tahun 2016

\begin{tabular}{cccc}
\hline No & Kriteria $O H I-S$ & Frekuensi & Persentase \% \\
\hline 1 & Baik & 5 & 14,7 \\
2 & Sedang & 26 & 76,5 \\
3 & Buruk & 3 & 8,8 \\
\hline & Total & 34 & 100
\end{tabular}

b. Persentase responden berperilaku menyikat gigi sangat baik, baik, cukup, dan perlu bimbingan

Tabel 2

PersentasePerilakuMenyikat Gigi SiswaKelas VI SDN 5 PekutatanTahun 2016

\begin{tabular}{cccc}
\hline No & Kriteria Perilaku Menyikat Gigi & Frekuensi & Persentase \% \\
\hline 1 & Sangat baik & 0 & 0 \\
2 & Baik & 0 & 0 \\
3 & Cukup & 0 & 0 \\
4 & Perlu bimbingan & 34 & 100 \\
\hline & Total & 34 & 100
\end{tabular}


c. Analisis kriteria $O H I-S$ berdasarkan perilaku menyikat gigi

Tabel 3

Persentase OHI-S Berdasarkan Perilaku Menyikat Gigi Siswa Kelas VI SDN 5

PekutatanTahun 2016

\begin{tabular}{|c|c|c|c|c|c|c|c|c|c|}
\hline \multirow{3}{*}{ No } & \multirow{3}{*}{ Kriteria } & \multicolumn{6}{|c|}{ KriteriaOHI-S } & \multirow{2}{*}{\multicolumn{2}{|c|}{ Total }} \\
\hline & & \multicolumn{2}{|c|}{ Baik } & \multicolumn{2}{|c|}{ Sedang } & \multicolumn{2}{|c|}{ Buruk } & & \\
\hline & & $\mathrm{n}$ & $\%$ & $\mathrm{n}$ & $\%$ & $\mathrm{n}$ & $\%$ & $\mathrm{n}$ & $\%$ \\
\hline 1 & Sangat baik & 0 & 0 & 0 & 0 & 0 & 0 & 0 & 0 \\
\hline 2 & Baik & 0 & 0 & 0 & 0 & 0 & 0 & 0 & 0 \\
\hline 3 & Cukup & 0 & 0 & 0 & 0 & 0 & 0 & 0 & 0 \\
\hline 4 & Perlu & 5 & 14,7 & 26 & 76,5 & 3 & 8,8 & 34 & 100 \\
\hline \multicolumn{8}{|c|}{ Jumlah } & 34 & 100 \\
\hline
\end{tabular}

\section{Pembahasan}

Berdasarkan hasil analisis data makanan akibatnya sisa makanan masih terhadap 34 siswa kelas VI SD No. 5 melekat sehingga dapat mempengaruhi Pekutatan Kecamatan Pekutatan pertumbuhan plak. Hal ini sesuai dengan Kabupaten Jembrana Tahun 2016, pendapat dari (5) menyatakan bahwa didapat hasil yaitu $O H I-S$ dari siswa faktor-faktor yang mempengaruhi kelas VI SD No. 5 Pekutatan yang kebersihan gigi dan mulut adalah plak. memiliki kriteria baik lima orang Pertumbuhan plak dipengaruhi oleh $(14,7 \%)$, kriteria sedang 26 orang waktu dan makanan, waktu yang cukup $(76,5 \%)$, kriteria buruk tiga orang untuk perkembangan plak didapatkan $(8,8 \%)$. Hasil ini menunjukkan bahwa bila seseorang mengabaikan tindakan kebersihan gigi dan mulut siswa kelas VI kebersihan gigi dan mulut sedangkan SD No. 5 Pekutatan Tahun 2016 makanan yang manis dapat terbanyak dengan kriteria sedang 26 mempengaruhi pertumbuhan plak. orang $(76,5 \%)$. Hal ini kemungkinan Hasil penelitian ini menunjukkan disebabkan karena responden bahwa 34 siswa (100\%) berperilaku mengabaikan tindakan kebersihan gigi menyikat gigi dengan kriteria perlu dan mulut seperti tidak sikat gigi dan bimbingan, hal ini kemungkinan berkumur-kumur setelah mengkonsumsi disebabkan karena seluruh responden 
memiliki perilaku menyikat gigi tidak benar, dilihat dari tehnik atau cara menyikat gigi, alat-alat untuk menyikat gigi, waktu menyikat gigi yang tidak benar. Hal ini sesuai dengan pendapat (6) menyatakan bahwa faktor-faktor yang mempengaruhi perilaku ada tiga faktor yaitu faktor predisposisi (predisposing factors) ini dipengaruhi oleh pengetahuan dan sikap masyarakat terhadap kesehatan, faktor pendukung ini mencakup ketersediaan sarana dan prasarana atau fasilitas pelayanan kesehatan, faktor pendorong (reinforcing factors) ini meliputi faktor sikap dan perilaku para tokoh masyarakat, tokoh agama, sikap dan perilaku para petugas termasuk petugas kesehatan. Ketiga faktor tersebut mempengaruhi perilaku menyikat gigi siswa kelas VI SD No. 5 Pekutatan Kecamatan Pekutatan Kabupaten Jembrana Tahun 2016.

Berdasarkan hasil penelitian dari 34 siswa yang kriteria $O H I-S$ baik sebanyak lima orang $(14,7 \%)$ dengan memiliki kriteria keterampilan menyikat gigi perlu bimbingan, kriteria $O H I-S$ sedang sebanyak 26 orang $(76,5 \%)$ dengan memiliki kriteria keterampilan menyikat gigi perlu bimbingan, kriteria OHI-S buruk sebanyak tiga orang $(8,8 \%)$ dengan memiliki kriteria keterampilan menyikat gigi perlu bimbingan. Menurut (7), faktor perilaku merupakan salah satu faktor yang mempengaruhi status kesehatan seseorang. Perilaku kesehatan terdiri atas perilaku tertutup seperti pengetahuan dan sikap terhadap kesehatan dan perilaku terbuka berupa tindakan atau praktek kesehatan seperti menyikat menyikat gigi sehingga pemeliharaan kesehatan gigi dan mulut indikatornya adalah variabel menyikat gigi yakni waktu dan tehnik menyikat gigi yang tepat (1). Hal ini sesuai dengan pendapat (8), yang menyatakan bahwa kebersihan gigi dan mulut dipengaruhi antara lain oleh faktor-faktor menyikat gigi dan jenis makanan yang dimakan.

Hasil penelitian menunjukkan bahwa siswa kelas VI SD No. 5 Pekutatan Kecamatan Pekutatan Kabupaten Jembrana Tahun 2016 terdapat $O H I-S$ dengan kriteria baik sebanyak lima orang, OHI-S dengan kriteria sedang sebanyak 26 orang, $O H I-$ $S$ dengan kriteria buruk sebanyak tiga orang. Tingginya perilaku menyikat 
gigi dengan kriteria keterampilan perlu bimbingan terutama dalam kesalahan tehnik menyikat gigi, hal ini kemungkinan disebabkan siswa belum mengerti tentang cara menyikat gigi yang benar. Kebersihan gigi dan mulut sering diabaikan sehingga terjadi penumpukan sisa makanan yang tentunya berpengaruh terhadap Oral Hygiene Index Simplified (OHI-S).

\section{Simpulan dan Saran}

Dari hasil penelitian yang dilakukan pada 34 siswa kelas VI SD No. 5 Pekutatan Kecamatan Pekutatan Kabupaten Jembrana Tahun 2016 maka dapat disimpulkan: Oral Hygiene Index Simplified pada siswa kelas VI SD No. 5 Pekutatan, Kecamatan Pekutatan, Kabupaten Jembrana Tahun 2016 yang memiliki kriteria OHI-S terbanyak adalah dengan criteria sedang. Perilaku menyikat gigi siswa kelas VI SD No. 5 Pekutatan Kecamatan Pekutatan Kabupaten Jembrana Tahun 2016 yang memiliki perilaku menyikat gigi terbanyak adalah siswa dengan criteria keterampilan perilaku menyikat gigi perlu bimbingan.

Diharapkan pada siswa SD No. 5 Pekutatan Kecamatan Pekutatan Kabupaten Jembrana khususnya siswa kelas VI agar selalu menyikat gigi dengan cara yang benar. Bagi orang tua siswa, agar memantau kebiasaan pelihara diri siswa, terutama dalam pemeliharaan kesehatan gigi dan mulut. Bagi Puskesmas yang mewilayahi SD No. 5 Pekutatan lebih sering mengadakan pelayanan khususnya di bidang promotif dan preventif. 


\section{Daftar Pustaka}

1. Sriyono, N.W. Pencegahan Penyakit Gigi dan Mulut Guna Meningkatkan Kualitas Hidup. Yogyakarta: Universitas Gadjah Mada, 2009.

2. RI, Kemenkes. Badan Penelitian dan Pengembangan Kesehatan. Jakarta: Kementerian Kesehatan RI, 2013.

3. Fitriani, L.S. OHI-S dan Perilaku Menyikat Gigi Siswa Kelas V SD Pelayanan Asuhan Keperawatan Gigi Poltekkes Denpasar. Denpasar: JKG Poltekkes Denpasar, 2013.

4. Depkes, RI. Survey Dasar Kesehatan Gigi dan Mulut (Oral Heart Surveys Basic Method, Thirt Edition. Jakarta : Direktorat Kesehatan Gigi, 1991.

5. K.N., Be. Preventive Dentistry Untuk Sekolah Pengatur Perawat Gigi I. Bandung: Yayasan Kesehatan Gigi Indonesia, 1987.

6. Notoatmojo, S. Promosi Kesehatan dan Perilaku Kesehatan. Jakarta: Rineka Cipta, 2012.

7. Promoting Healthy Behavior, Population References Bureau. Murphy, E.M. s.l. : Healt Buletin, 2004.

8. Suwelo, I.S. Karies Gigi Pada Anak dengan Berbagai Faktor Etologi. Jakarta : EGC, 1992. 